\title{
LUTEINIZING HORMONE CONCENTRATIONS IN THE PLASMA OF LAYING HENS EXPOSED TO A 27-HR CYCLE OF LIGHT AND DARKNESS
}

\author{
T. R. MORRIS, O. MELEK AND F. J. GUNNINGHAM*
}

Department of Agriculture and Horticulture, and *Department of Physiology and Biochemistry, The University, Reading RG6 2AT

(Received 16th Fuly 1974)

\begin{abstract}
Summary. The time of peak concentration of $\mathrm{LH}$ in the peripheral plasma of ten laying hens kept on a $14 \mathrm{hr}$ light $/ 13 \mathrm{hr}$ dark cycle was determined by radioimmunoassay. A single peak of $\mathrm{LH}$ occurred in each hen $3 \frac{1}{2} \mathrm{hr}$ before oviposition or $4 \mathrm{hr}$ before ovulation. These are similar intervals to those reported for laying hens kept on a $14 \mathrm{hr}$ light $/ 10 \mathrm{hr}$ dark cycle. The mean time of the observed peak in plasma $\mathrm{LH}$ was $2 \mathrm{hr}$ $9 \mathrm{~min}$ after the beginning of the dark period. This is about $3 \mathrm{hr}$ earlier than corresponding LH peaks reported for hens under normal lighting.
\end{abstract}

Ovulation in the hen, as in mammals, is induced by release of LH from the anterior pituitary. This release is regulated by a neuroendocrine control mechanism (Fraps, 1955, 1961) which results in ovulation being restricted to a period of about $8 \mathrm{hr}$ in each day. Recently, Furr, Bonney, England \& Cunningham (1973) and Wilson \& Sharp (1973), using a radioimmunoassay specific for chicken LH, established that a single peak in the concentration of plasma $\mathbf{L H}$ occurs 7 to $4 \mathrm{hr}$ before ovulation in hens exposed to photoperiods of $14 \mathrm{hr}$ light/ $10 \mathrm{hr}$ dark.

In hens exposed to ahemeral light cycles, i.e. periods of light and darkness which do not add up to $24 \mathrm{hr}$, the pattern of oviposition can readily be entrained to follow cycles in the range from 21 to $30 \mathrm{hr}$ (Biellier \& Ostmann, 1960; Morris, 1973). In hens exposed to a 27-hr cycle of light and darkness, both the time spent by the egg in the oviduct and the interval from oviposition to next ovulation are longer than in hens maintained under normal conditions (Melek, Morris \& Jennings, 1973). Ovulation and oviposition both occur in the dark period when hens are exposed to a 27-hr light/dark schedule, whereas on a 24-hr lighting schedule these events usually occur in the light phase (Morris, 1973). Since many of the familiar time relationships of the ovulatory cycle are displaced in hens exposed to a $27-\mathrm{hr}$ cycle, it was of interest to determine the time of occurrence of the peak concentration of $\mathrm{LH}$ in such birds in relation to the time of ovulation and the onset of darkness.

White Leghorn (Shaver 288) pullets kept in light-proof rooms were subjected to a 27-hr lighting schedule (14 hr light/13 hr dark) beginning at 58 weeks of age. The birds were housed in individual cages fitted with automatic recording devices which timed ovipositions to the nearest minute. After 15 days, twelve 
birds with regular patterns of lay were selected. Blood $(2 \mathrm{ml})$ was withdrawn from the brachial vein into a heparinized syringe between 08.22 and 09.39 hours. Five further samples were taken from each bird at consecutive intervals of about $2 \mathrm{hr}$, the exact time of bleeding being recorded in each case. The dark period began at 14.00 hours on the day of sampling so that the last three samples were taken during this period but before most ovipositions had occurred. In hens exposed to 27-hr cycles, eggs are laid in the last half of the dark period.

The heparinized blood was centrifuged for $15 \mathrm{~min}$ at $600 \mathrm{~g}$ immediately after collection and the plasma was separated and stored at $-20^{\circ} \mathrm{C}$ until assay. Plasma concentrations of $\mathrm{LH}$ were determined in a single radioimmunoassay (Follett, Scanes \& Cunningham, 1972), using as standard a purified preparation of chicken LH described by Stockell-Hartree \& Cunningham (1969).

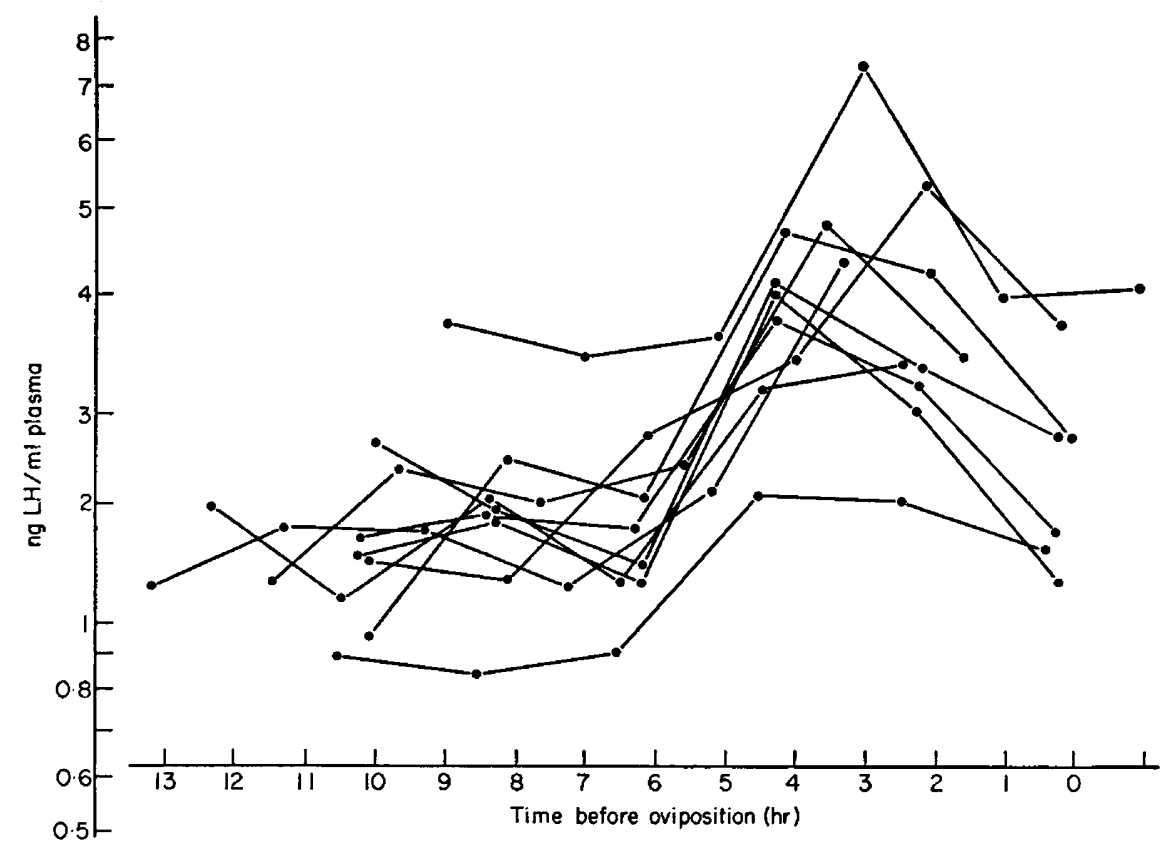

TexT-Fig. 1. Concentrations of $\mathrm{LH}$ in the plasma of ten laying pullets exposed to a $27 \mathrm{hr}$ light/dark cycle. Of the six plasma samples obtained from each bird, the first three samples were taken during the light period and the last three samples were taken during the dark period.

All hens laid normally on the day of blood sampling at times between 17.32 and 22.37 hours with a mean of 20.02 hours, i.e. $6 \mathrm{hr}$ after the beginning of the dark period. Eleven of the hens laid again in the following cycle with a mean oviposition time of 23.49 hours $(6 \mathrm{hr} 49 \mathrm{~min}$ after the beginning of the dark period). The hen which failed to lay was omitted from the results since it is uncertain whether ovulation occurred on the day that blood was withdrawn.

The plasma LH concentrations for ten hens are shown in Text-fig. 1. (Incomplete data for an eleventh hen were discarded.) Each of the hens had a characteristic basal level of plasma LH and, within the period studied, each 
showed a single peak of LH which occurred between 4 and $2 \mathrm{hr}$ before oviposition; in most cases, during the first $2 \mathrm{hr}$ of the dark period. Some hens showed a comparatively small rise in $\mathrm{LH}$ at this time but with samples taken at 2-hr intervals, it was possible to miss the maximum concentration if it was of short duration.

The data were divided into arbitrary periods as shown in Table 1 and were subjected to an analysis of variance. The use of a logarithmic response metameter and the removal of average bird effects both helped to reduce the heterogeneity of variances for different periods. The standard errors in Table 1 were calculated from the pooled estimate of variance. The data showed that the increases in mean plasma LH concentration between 7 to $5 \mathrm{hr}$ and 5 to $3 \mathrm{hr}$ before oviposition were highly significant $(P<0.001)$.

Table 1. Concentrations of plasma LH at various times before oviposition in White Leghorn hens exposed to a $27-\mathrm{hr}$ ahemeral cycle

\begin{tabular}{|c|c|}
\hline $\begin{array}{c}\text { Time before } \\
\text { oviposition (hr) }\end{array}$ & $\underset{\langle n g / m l)}{L H}$ \\
\hline $\begin{array}{c}15 \text { to } 13 \\
13 \text { to } 11 \\
11 \text { to } 9 \\
9 \text { to } 7 \\
7 \text { to } 5 \\
5 \text { to } 3 \\
3 \text { to } 1 \\
1 \mathrm{hr} \text { before } \\
\text { to } 1 \mathrm{hr} \text { after }\end{array}$ & $\begin{array}{l}1 \cdot 14(1)^{*} \\
1 \cdot 34 \pm 0.050 \quad(3) \\
1 \cdot 36 \pm 0.027(10) \\
1 \cdot 42 \pm 0.027(10) \\
1 \cdot 45 \pm 0.027(10) \\
3 \cdot 03 \pm 0.027(10) \\
2 \cdot 49 \pm 0.028(9) \\
1 \cdot 77 \pm 0.033(7)\end{array}$ \\
\hline
\end{tabular}

The mean interval \pm S.E. from the highest plasma $\mathrm{LH}$ concentrations observed for each hen to the next oviposition was $3 \mathrm{hr} 36 \mathrm{~min} \pm 16 \mathrm{~min}$. Since the mean interval from oviposition to ovulation for hens maintained under a $27-\mathrm{hr}$ cycle is $36 \mathrm{~min} \pm 8 \mathrm{~min}$ (Melek et al., 1973), the best estimate of time from peak LH concentration in the plasma to ensuing ovulation in these birds is about $4 \mathrm{hr}$. The time of occurrence of the LH peak in relation to ovulation in these birds was similar, therefore, to that seen in birds kept on a 24-hr lighting regimen (Furr et al., 1973; Wilson \& Sharp, 1973).

The timing of the LH peak relative to the dark period was not the same as that reported for hens in normal lighting conditions. Under the $27-\mathrm{hr}$ regimen, six out of ten birds showed a maximum plasma LH concentration in the first $2 \mathrm{hr}$ of the dark period and all hens showed a peak within $6 \mathrm{hr}$. The mean time \pm S.E. of the observed LH peak was $2 \mathrm{hr} 9 \mathrm{~min} \pm 34 \mathrm{~min}$ after the beginning of the dark period. Wilson \& Sharp (1973) have shown that, under 24-hr cycles, peak plasma LH values occur between $4 \mathrm{hr}$ and $13 \mathrm{hr}$ after the onset of darkness, although this range includes both first and last ovulations in a sequence. It can be calculated from Wilson \& Sharp's data that follicles which formed the first 
egg of a sequence ovulated in response to an LH peak occurring at a mean time of $4 \mathrm{hr} 40 \mathrm{~min} \pm 18 \mathrm{~min}$ after the beginning of the dark period. The data presented here are therefore consistent with the view (Morris, 1973) that, under 27-hr cycles, the time of the LH peak is advanced by about $3 \mathrm{hr}$ compared with the time of the $\mathrm{LH}$ peak associated with the first ovulation of a sequence in hens maintained under 24-hr lighting conditions.

\section{REFERENCES}

Biellier, H. V. \& OstmanN, O. W. (1960) Effect of varying daylength on time of oviposition in domestic fowl. Bull. Univ. Mo. Agric. Exp. Stn, No. 747.

Follett, B. K., Scanes, G. G. \& Cunningham, F. J. (1972) A radio-immunoassay for avian luteinizing hormone. 7. Endocr. 52, 359-378.

Fraps, R. M. (1955) Egg production and fertility in poultry. In Progress in the Physiology of Farm Animals, Vol. 2, pp. 661-740. Ed. J. Hammond. Butterworths, London.

FraPs, R. M. (1961) Ovulation in the domestic fowl. In Control of Ovulation, pp. 135-167. Ed. C. A. Villee. Pergamon Press, London.

Furr, B. J. A., Bonney, R. G., England, R. J. \& Gunningham, F. J. (1973) Luteinizing hormone and progesterone in peripheral blood during the ovulatory cycle of the hen, Gallus domesticus. $\mathcal{J}$. Endocr. 57, 159-169.

Melek, O., Morris, T. R. \& Jennings, R. G. (1973) The time factor in egg formation for hens exposed to ahemeral light-dark cycles. Br. Poult. Sci. 14, 493-498.

Morris, T. R. (1973) The effects of ahemeral light and dark cycles on egg production in the fowl. Poult. Sci. 52, 423-445.

Stockeld-Hartree, A. \& Gunningham, F. J. (1969) Purification of chicken pituitary follicle-stimulating hormone and luteinizing hormone. 7 . Endocr. 43, 609-616.

Wilson, S. G. \& Sharp, P. J. (1973) Variations in plasma LH levels during the ovulatory cycle of the hen, Gallus domesticus. J. Reprod. Fert. 35, 561-564. 